\title{
The Effect of Cognitive-Behavioral Group Therapy on Decrease in Addiction Relapse in Randomly Assigned Addicts under Drug Therapy: A Statistical Analysis
}

Tahereh Mesrahi ${ }^{1 *}$, Mohammadreza Sedighi ${ }^{2}$ and Masoumeh Shirali ${ }^{3}$

${ }^{1}$ Department of Psychology, Karaj Branch, Islamic Azad University, Karaj, Iran

${ }^{2}$ Young Researchers Club, Buinzahra Branch, Islamic Azad University, Buinzahra, Iran

${ }^{3}$ Department of English Language, Islamic Azad University, Buinzahra branch, Buinzahra, Iran

\begin{abstract}
In order to study the effect of group therapy on decrease in addiction relapse, two groups, experimental and control group were used. The study population included all drug addicts referred to Addiction Quitting Center of Karaj. Twenty four of them who referred to center and received methadone were chosen as a convenient sample. Among them, a 12 person group participated in group therapy in addition to receiving methadone. Subjects were randomly divided into experimental and control groups. In order to collect data, questionnaires were used that provided demographic information including age, education, the age when drug abuse began, marital status, occupation, the type of drugs being abused and the abusing method, and also a morphine test in order to measure relapse times during therapy period. In order to carry out a descriptive analysis for subjects based on demographic variables and test variable frequency distribution table, mean, standard deviation and standard error of mean estimation and in order to carry out deductive analysis and hypothesis tests in dependent t-tests two-way variance analysis and Schaffer post hoc test were used. The findings of present study showed that there was a significant difference between the 2 groups in relation to addiction relapse and interaction of therapy methods with age and education exerted different effects on decrease in addiction relapse, but therapy methods together with marital status and occupation had no different effects on decrease in addiction relapse. Thus, the overall conclusion of present research is that the rate of decrease in relapse is greater in addicts under both drug therapy and group therapy than those who were only under drug therapy. Thus, it can be said that employing psychological therapies, especially Cognitive-Behavioral Group Therapy, is necessary for addicts under medical therapies and these types of therapies yield efficiency in both money and time respects.
\end{abstract}

Keywords: Group therapy; Addiction relapse; Methadone treatment; Cognitive-behavioral therapy

\section{Introduction}

Drug abuse and addiction to mood changing substances is one of the most significant social-psychological pathologies that can easily undermine individual, family, social and cultural bases of a country, endanger human dynamics and deteriorate material and spiritual resources. Drug abuse and addiction are complex disorders accompanied by spiritual, social, psychological and biological causes and effects [1]. One of the widely used therapies is main tenant Methadone treatment. Methadone is a synthetic opium-like substance with long term effect which is more effective in oral administration [2]. More than $80 \%$ of studies performed in relation to drug abuse and addiction concluded that effective therapies for drug abuse are those which use both biological and behavioral components [3].

Relapse (return to abuse) causes problems not only for the addict but also his/her family feel the failure and think that drug therapy was not effective because in this stage, the addict returns to addiction more deeply and widely than before [4]. According to Allen Marlart et al. [5], probability of recurrence in the most optimistic case is $50 \%$, and according to them this probability may range up to $90 \%$. According to Marlart and et al. [5], relapse or return is a continuous phenomenon and according to Coleman [6], the drug addict should be prepared for treatment both physically and individually. Addicts are often afraid of physiological consequences of quitting addiction.

According to Coleman [6], despite using therapeutic consultation and other rehabilitative measures, only $15 \%$ of addicts do not return to addiction after discharge from hospital. Thus, psychological treatment interventions e.g. group therapy, are among necessities of addiction treatment and should continue up to complete recovery of the patient. Although various psychological treatments including psychotherapy of individual, behavioral, cognitive and etc. are employed, it has been demonstrated that group therapy creates conditions and changes during treatment including: hope to overcome drug abuse problem, obtaining information and being aware of others having similar problems, decrease in feeling isolated, creation of sense of altruism and helping others in solving problems, changing incorrect conceptions about oneself, nurturing socialization techniques, learning techniques and skills of communicating with others, making examples of appropriate behavior and gaining opportunities for compensating family experiences and creating behavioral, emotional and cognitive changes [1].

In this paper we have conducted a study using Cognitive-Behavioral Group Therapy (CBGT) together with main tenant therapies for addicts under treatment on the basis of an investigation plan developed by Carroll et al. [3] in National Institution of Drug Abuse (NIDA) in order to contribute to existing knowledge on treatment and reduction of addiction relapse and employing the above-said plan in treatment

*Corresponding author: Tahereh Mesrahi, Department of Psychology, Karaj Branch, Islamic Azad University, Karaj, Iran, Tel: 989388871941; E-mail: tmesrahi@gmail.com

Received June 01, 2016; Accepted June 15, 2016; Published June 22, 2016

Citation: Mesrahi T, Sedighi M, Shirali M (2016) The Effect of Cognitive-Behavioral Group Therapy on Decrease in Addiction Relapse in Randomly Assigned Addicts under Drug Therapy: A Statistical Analysis. Int J Neurorehabilitation 3: 214. doi:10.4172/2376-0281.1000214

Copyright: @ 2016 Mesrahi T, et al. This is an open-access article distributed under the terms of the Creative Commons Attribution License, which permits unrestricted use, distribution, and reproduction in any medium, provided the original author and source are credited. 
centers by other consultants and therapists. Thus, the research hypotheses consist of:

\section{Primary aim}

There is a difference in rates of addiction relapse for addicts under drug therapy and group therapy.

\section{Secondary hypotheses}

1. Therapeutic methods have different effects on decrease in addiction relapse in various age groups.

2. Therapeutic methods have different effects on decrease in addiction relapse for different drug abuse beginning age group.

3. Therapeutic methods have different effects on decrease in addiction relapse based on marital status.

4. Therapeutic methods have different effects on decrease in addiction relapse according to occupation.

5. Therapeutic methods have different effects on decrease in addiction relapse based on education level.

\section{Experimental and Theoretical Framework}

Some studies were conducted on the effect of CBGT on decrease in addiction Eurocurrency. Schuckit [7] examined individuals who had a positive background for drug abuse with respect to their family. The results showed worthwhile finding on CBGT relationship with decrease in relapse and depression. In a research conducted by Carroll et.al [3], therapeutic model of CBGT and clinical management (CM) therapy were studied associated with their relationship with decrease in relapse and depression and the results showed that CBGT method is more effective in decrease in relapse and emotional disorders than CM. 28 female and male drug abusers were studied by Rezaei [8]. These individuals were placed in 2 test groups (14 ones in CBGT plus drug therapy) and a control group (14 ones in drug therapy). Results showed that cognitive behavioral group therapy (CBGT) played a significant role in decrease in relapse rate in drug abusers and depression scores significantly decreased in experimental group. Mehrabi et al. [9] was studied efficacy of group therapy and family training in decrease in addiction relapse in pre-test and post-test method. Test group consisted of subjects received 8 group therapy sessions and their spouses received an 8-session course of family training. Second group (control group) consisted of detoxify patients of same center randomly selected among others and did not receive mentioned interventions. Results suggested that group therapy and family training led to a significant decrease in temptation and tendency to return to drug abuse in post-test stage.

A research was conducted on 300 addicts under psychological (group therapy) and drug therapy, it was shown that marriage is an aiding factor in addiction treatment and age has effects on resistance to return and decrease in relapse. However, Yazdanfar [10] showed that there was not significant relationship between gender, age, education, type of substance, beginning age, marital status and treatment type in decrease of relapse rate. Also, in another research, in relation to social factors associated with addiction and relapse, result showed that there were significant relationship between afflicting with addiction and age, occupation, gender and marital status, but in study by Heidari [11] it was shown that during treatment period marital status had no significant effect on addiction relapse and in another study by Asadi [12] on participation in N.A. addict groups, results showed that demographic factors including occupation and education were not significant influence in relation to relapse rate.
As observed above, the studies emphasize the necessity of psychological treatments, especially group therapy, in addition to drug therapy at addiction quitting centers in order to decrease relapse rate. Also in present research it was tried to demonstrate that using CBGT with major emphasis on learning and practicing wide range of skills and in some cases changes in patient thoughts, is so effective in treatment and decrease relapse for addicts under drug therapies and also employment of this treatment method (CBGT) is in such a way that education level and age interacts with therapy in relation to effect on decrease in relapse.

\section{Method}

Based on primary aim of present study, i.e., identification of influence of group therapy on decrease in relapse for addicts under drug therapy, a semi-empirical method was used. In present research, semi-experimental design with two therapy groups and a post test was used whose diagram is as follows: Statistical population consisted of all addicts referred to specialized clinic of AtieNO of Karaj in order to quit drug addiction. Among them 24 addicts referred to center and received methadone were selected as a convenient sample. Among them 12 addicts were randomly assigned to a "methadone plus group therapy" group and another 12 addicts formed control group.

\section{Research instrument}

Research Instruments were a questionnaire, which was used to obtain demographic information based on variables: age, education, drug abuse beginning age, marital status, occupation, narcotic types and administration method of substances, and also morphine test conducted by a professional center every week.

\section{Data analysis}

In present study in order to carry out descriptive analysis of sample based on demographic variables and test variables, frequency distribution table, mean, standard deviation and standard error of mean estimation were used and for deductive analysis and hypothesis tests independent t-test, two-way variance analysis and Schaffe's posthoc analysis were used.

\section{Results}

\section{Descriptive analysis}

Table 1 presents the descriptive indices of test and control groups in according to their age as well as age of beginning drug abuse. Also, frequency distribution of groups categorized into four groups of job, type of consumed narcotics, method of application and marital status are shown in Table 2.

\section{Inferential analysis}

Principal hypothesis: There is different between relapse addiction

\begin{tabular}{|c|c|c|c|c|}
\hline Groups & $\mathbf{n}$ & $\overline{\boldsymbol{x}}$ & Min & Max \\
\hline Age & \multicolumn{5}{|l}{} \\
\hline Test & 12 & 30.16 & 20 & 45 \\
\hline Control & 12 & 33.58 & 23 & 50 \\
\hline Age of onset drug abuse & \multicolumn{5}{|}{} \\
\hline Test & 12 & 24.5 & 15 & 38 \\
\hline Control & 12 & 25.18 & 15 & 40 \\
\hline
\end{tabular}

Table 1: Descriptive indices of studied groups based on age and age of beginning drug abuse. 


\begin{tabular}{|l|c|c|c|c|}
\hline Subjects Characteristics & Test & Control & & \\
\hline & $\mathbf{n}(\%)$ & $\mathbf{n}(\%)$ & $\mathbf{n}$ & $\%$ \\
\hline Education & & & & \\
\hline Lower than diploma & $5(42)$ & $5(42)$ & & \\
\hline Diploma & 5 & 42 & 4 & 33 \\
\hline B.A. and higher & 2 & 16 & 3 & 25 \\
\hline Job & & & & \\
\hline Self-employed & 5 & 42 & 7 & 58 \\
\hline Governmental & 3 & 25 & 2 & 17 \\
\hline Unemployed & 4 & 33 & 3 & 25 \\
\hline Type of narcotics & & & & \\
\hline Opium Sheereh & & 8 & 4 & 33 \\
\hline Opium, Heroin and Sheereh & 1 & 0 & 2 & 17 \\
\hline Opium, Crack Sheereh & 0 & 8 & 3 & 25 \\
\hline Opium and heroin & 1 & 17 & 2 & 17 \\
\hline Opium, Heroin, Crack and Sheereh & 2 & 0 & 1 & 8 \\
\hline Opium & 1 & 8 & 0 & 0 \\
\hline Opium and Crack & 4 & 34 & 0 & 0 \\
\hline Opium, Heroin and Crack & 3 & 25 & 0 & 0 \\
\hline Application & & & & \\
\hline Edible, fumigation & 2 & 17 & 10 & 84 \\
\hline Edible, fumigation, injection and venose & 2 & 17 & 0 & 0 \\
\hline Fumigation, venose and injection & 4 & 33 & 1 & 8 \\
\hline $\begin{array}{l}\text { Edible, fumigation, injection, venose and } \\
\text { inhaling }\end{array}$ & 0 & 0 & 1 & 8 \\
\hline Non-venose injection & 0 & 0 & 0 & 0 \\
\hline Fumigation & 4 & 33 & 0 & 0 \\
\hline Marital status & 4 & 33 & 7 & 58 \\
\hline Married & 8 & 67 & 5 & 42 \\
\hline Single & & & \\
\hline bion & & & \\
\hline
\end{tabular}

${ }^{1}$ boiled and refined opium residue

Table 2: Frequency distribution of groups.

\begin{tabular}{|c|c|c|c|c|c|c|}
\hline Groups & $\mathbf{n}$ & $\bar{x}$ & $\mathbf{s}$ & $S_{x 1-x 2}$ & $\mathbf{t}$ & $F_{c}$ \\
\hline Test & 12 & 4.08 & 0.79 & 0.59 & $|-5.23|$ & 4.33 \\
\hline Control & 12 & 7.17 & 3.42 & 0.59 & 4.40 \\
\hline
\end{tabular}

Table 3: Independent T-test for comparing level of relapse.

of junkie treated by medicine and group therapy. In order to test the hypothesis, it is applied from Independent T-test for comparing level of relapse at test group and control group by using description mentioned at Table 3.

According to the results of Table $3, \mathrm{Fo}<\mathrm{Fc}$ therefore there is hypothesis of equity for variances at level of 0.01 and it is possible to apply Independent T-test for comparing averages. Result of T-test at Table 3 shows that absolute value of $\mathrm{T}$ is obtained from $\mathrm{T}$ table at the level of 0.01 by having degree of freedom ( $t c=2.845) 22$, i.e., the null hypothesis is rejected and research hypothesis as decreasing relapse of addiction through group therapy is confirmed.

First subsidiary hypothesis: In order to test the hypothesis, the groups under this study were divided into 2 groups, i.e., a group of 30 year old and younger and a group of older than 30 that were interacted with treatment groups to establish 4 groups that by using variance analysis the average of 4 groups was compared and its results are offered at Table 4.

According to the results of Table 4: level of F statistics is 3.62 that is greater than critical $\mathrm{F}(\mathrm{F} 0.5,3.20=3.10)$ and it is possible to say that interaction between age of subjects and type of treatment is effective on decreasing relapse of addiction. To compare averages of double groups, Shaffe's test is applied. Its results are offered in Table 5.

Results of Table 5 show that only there is significant difference among subjects with age of 30 and younger among methadone therapy group and group therapy at the level of 0.05 . Thus, age of addicted persons with treatment methods does not determine the reduction of relapse. It is to be noted that comparing 2 groups with respect to their age and following data is not significant. Results are offered at Table 6.

Level of obtained $t(|0.5|)$ is smaller than $t$ table with degree of freedom as 22 and significance level of 0.05 (1.96) as represented in Table 6, therefore, it is concluded that there is no significant difference between two groups with respect to their age.

Second subsidiary hypothesis: Age of beginning consuming narcotics and treatment methods are effective on reducing relapse of

\begin{tabular}{|c|c|c|c|c|c|}
\hline Resource change & ss & DOF & MS & $\mathbf{F}$ & $F_{c}$ \\
\hline \multicolumn{6}{|c|}{ First subsidiary hypothesis } \\
\hline Inter-group & 62.49 & 3 & 20.83 & \multirow{2}{*}{3.62} & \multirow{2}{*}{$F_{0.05,3.20}=3.10$} \\
\hline Intra-group & 115.13 & 20 & 5.76 & & \\
\hline Total & 177.62 & 23 & - & & \\
\hline \multicolumn{6}{|c|}{ Marital and treatment methods } \\
\hline Inter-group & 54.09 & 3 & 18.03 & \multirow{2}{*}{2.902} & \multirow{2}{*}{$F_{0.05,3.20}=3.10$} \\
\hline Intra-group & 123.53 & 20 & 6.176 & & \\
\hline Total & 177.62 & 23 & - & & \\
\hline \multicolumn{6}{|c|}{ Job and treatment method } \\
\hline Inter-group & 75.40 & 5 & 15.08 & \multirow{2}{*}{2.65} & \multirow{2}{*}{$F_{0.05,5.18}=2.77$} \\
\hline Intra-group & 102.22 & 18 & 5.67 & & \\
\hline Total & 177.62 & 23 & - & & \\
\hline \multicolumn{6}{|c|}{ Education and treatment methods } \\
\hline Inter-group & 72.41 & 3 & 24.13 & \multirow{2}{*}{4.58} & \multirow{2}{*}{$F_{0.05,3.20}=3.10$} \\
\hline Intra-group & 105.21 & 20 & 5.26 & & \\
\hline Total & 177.62 & 23 & - & & \\
\hline
\end{tabular}

Table 4: Summary of two-way variance analysis for subsidiary hypotheses.

\begin{tabular}{|l|c|c|c|c|}
\hline & $\begin{array}{c}\text { 30 years and } \\
\text { younger- } \\
\text { CBGT }\end{array}$ & $\begin{array}{c}\text { 30 years and } \\
\text { younger- MT }\end{array}$ & $\begin{array}{c}\text { Older than } \\
\text { 30 years- } \\
\text { CBGT }\end{array}$ & $\begin{array}{c}\text { Older } \\
\text { than 30 } \\
\text { years- MT }\end{array}$ \\
\hline 30 years and younger - CBGT & - & - & & \\
\hline 30 years and younger - MT & 3.10 & - & & \\
\hline Older than 30 years - CBGT & $1-0.67 \mid$ & 1.88 & - & \\
\hline Older than 30 years - MT & 1.88 & - & - & \\
\hline
\end{tabular}

MT=Methadone Therapy

Table 5: Comparing average of groups by using Shaffe's test.

\begin{tabular}{|l|l|l|l|l|l|}
\hline Groups & $\mathbf{n}$ & $\bar{x}$ & $\mathbf{s}$ & $S_{\bar{x}}$ & $\mathbf{t}$ \\
\hline Age & & & & & \\
\hline 30 years and younger & 14 & 5.43 & $\begin{array}{l}10.09 \\
3.176\end{array}$ & \multirow{2}{*}{0.94} & 0.5 \\
\hline Older than 30 years & 10 & 5.9 & $\begin{array}{l}4.98 \\
2.23\end{array}$ & & \\
\hline Age of begin consuming narcotics & & & & & \\
\hline Younger than 25 years & 13 & 5.84 & 3.10 & \multirow{2}{*}{0.15} & 0.42 \\
\hline Older than 25 years & 10 & 5.9 & $\begin{array}{l}4.98 \\
2.23\end{array}$ & & \\
\hline
\end{tabular}

Table 6: Comparing treatment results for age groups and age of begin consuming narcotics under this study. 
addiction. Calculated $\mathrm{t}(|0.5|)$ is smaller than $\mathrm{t}$-table with degree of freedom as 22 and significance level of 0.05 (1.96) which are shown in Table 6. Consequently, there is no significant difference between two groups based on age of beginning consuming narcotics.

Third subsidiary hypothesis: Method of treatment according to marital status has different effect on decreasing addiction relapse. In order to test this hypothesis, all of the descriptive data are offered in Table 7.

Four groups are created by mixing marital status and treatment methods. We used two-way analysis of variance technique for the comparison of average. The results are offered in Table 4 .

Results of table 4 show that, interaction of marital status with method of treatment is not effective on reducing addiction relapse; since, level of $F(2.92)$ is smaller than critical $F$ with 20 and 3 degrees of freedom and the significance level is 0.05 (3.20).

Fourth subsidiary hypothesis: Job status of addicted persons and method of treatment is effective on reducing addiction relapse. For hypothesis test, the groups under this study were divided into 3 groups including: governmental job, self-employed and unemployed and by using 2 treatment methods, it established 6 groups for obtaining descriptive data as mentioned in the Table 7 . The average reducing relapse (governmental-group therapy=3) shows the lowest and (governmental-group therapy $=8$ ) shows the highest amount i.e. level of reducing relapse at (governmental-group therapy) is higher than other groups; however, for the first hypothesis test, the two-way variance analysis is used and its results are offered in Table 4.

Level of $\mathrm{F}$ (2.65) is smaller than critical F (2.77); therefore, it is concluded that; mixing job and treatment method is not effective on reducing relapse of addiction as represented in Table 4 .

\begin{tabular}{|l|c|c|c|c|}
\hline Groups & $\mathbf{n}$ & $\bar{x}$ & $\mathbf{S}$ & $S_{\bar{x}}$ \\
\hline Marital and treatment methods & & & & \\
\hline Single - CBGT & 8 & 4.57 & 0.93 & 0.33 \\
\hline Single-Methadone therapy & 5 & 8.2 & 3.57 & 1.59 \\
\hline Married - CBGT & 4 & 4.25 & 2.63 & 1.31 \\
\hline Married - Methadone therapy & 7 & 6.42 & 4.65 & 1.76 \\
\hline Total & 24 & 5.62 & 2.78 & 0.56 \\
\hline Job and treatment method & & & & \\
\hline Governmental - group therapy & 3 & 3 & 0 & 0 \\
\hline Governmental - Methadone therapy & 2 & 8 & 3.85 & 2.73 \\
\hline Self-employed - CBGT & 5 & 5.4 & 1.08 & 0.48 \\
\hline Self-employed - Methadone therapy & 7 & 7.28 & 4.02 & 1.52 \\
\hline Unemployed - group therapy & 4 & 3.25 & 1.65 & 0.76 \\
\hline Unemployed - Methadone therapy & 3 & 6.33 & 1.53 & 0.88 \\
\hline Education and treatment methods & & & & \\
\hline Lower than diploma - CBGT & 5 & 4.6 & 2.07 & 0.48 \\
\hline Lower than diploma - Methadone therapy & 5 & 8.4 & 3.91 & 1.75 \\
\hline Diploma and higher - CBGT & 7 & 3.71 & 2.72 & 1.03 \\
\hline Diploma and higher - Methadone therapy & 7 & 6.28 & 1.71 & 0.65 \\
\hline
\end{tabular}

Table 7: Descriptive indices for mixed groups.
In order to determine whether double groups have significant difference or not, 2 groups with lowest and highest average were compared. Comparison of (governmental-group therapy) group and (governmental-methadone therapy) group was performed by using Schaffe's test and the following amount was obtained:

$$
t=\frac{\left|\overline{x_{1}}-\overline{x_{2}}\right|}{\sqrt{M S_{w}\left(\frac{w_{1}^{1}}{n_{1}}+\frac{w_{2}^{2}}{n_{2}}\right)}}=\frac{18-21}{\sqrt{5 / 67\left(\frac{1}{3}+\frac{1}{2}\right)}}=\frac{|5|}{2 / 17}=2 / 30
$$

$t_{c}(2.30)$ is smaller than $t_{\alpha}(3.72)$; therefore, there is no significant difference between lowest and highest average i.e. job and treatment method are not regarded as effective factor for decreasing addiction relapse.

Fifth subsidiary hypothesis: Method of treatment according to level of education has different effect on decreasing addiction relapse. In order to test this hypothesis, all of the subjects under this study were divided into two groups according to their education, including: groups with education higher than secondary education diploma and group with education lower than secondary education diploma and then based on mixing their education and treatment methods, they were divided into 4 groups whose descriptive data is offered in Table 7 .

Reducing relapse at mixed group (diploma and higher - group therapy) is the highest level $(\bar{x}=3.71)$ and at

group of (education lower than secondary school diplomamethadone therapy) is the lowest level $(\bar{x}=8.4)$ and for comparing averages of 4 mixed groups with respect to level of education and treatment method, a two-way variance analysis is used. The results are offered at Table 8 .

Results of Table 8 show that level of F (4.58) is greater than critical $F$ with 20 and 3 degrees of freedom and significance level of 0.05 (3.10). Thus, null hypothesis is rejected with $95 \%$ certainty and research hypothesis is confirmed i.e. interaction of education with treatment methods have different effects on reducing addiction relapse. We applied from schaffe's test in order to determine whether 4 groups have significant difference or not.

Data of Table 8 show that:

1) Whereas $t_{c}(0.58)$ is smaller than $t_{\alpha}(3.04)$ it is concluded that there is no significant difference between 2 groups

2) Whereas $t_{c}(2.62)$ is smaller than $t_{\alpha}(3.04)$ it is concluded that there is no significant difference between 2 groups

3) Whereas $t_{c}$ (3.5) is greater than $t_{\alpha}$ (3.04) it is concluded that there is significant difference between 2 groups

4) Whereas $t_{c}(2.10)$ is smaller than $t_{\alpha}(3.04)$ it is concluded that there is significant difference between 2 groups

\section{Discussion and Conclusion}

In this research, two groups: Group therapy- Methadone therapy group and Methadone therapy group are studied. The test group "Group

\section{Groups}

1. (Lower than diploma - CBGT) and (diploma and higher - CBGT)

2. (Lower than diploma - CBGT) and (lower than diploma - Methadone therapy)

3. (Diploma and higher - CBGT) and (lower than diploma-Methadone therapy)

4. (Diploma and higher - CBGT) and (diploma and higher-Methadone therapy)

\begin{tabular}{|c|c|c|}
\hline$t_{c}$ & $t_{\alpha}$ & Results \\
\hline 0.58 & 3.04 & $t_{\alpha}<t_{c}$ \\
\hline 5 & 8.4 & $t_{\alpha}<t_{c}$ \\
\hline 7 & 3.71 & $t_{\alpha}<t_{c}$ \\
\hline 7 & 6.28 & $t_{\alpha}<t_{c}$ \\
\hline
\end{tabular}

Table 8: Comparing average 4 groups by using Schaffe's test. 
therapy+Methadone therapy group" remedied for 16 sessions that is 24 h. Morphine test did for two groups once in a weak. The result showed that there is a significant difference in reducing addiction relapse. Remedial methods with age and education degree have had different effect on reducing addiction relapse, but remedial method with marital status, job and the onset of drug use could not have different effect on reducing addiction relapse. The finding will be discussed according to hypothesis and research background.

Based on the main hypothesis investigation results, there is difference in addiction relapse rate of the addicted under remedy of group therapy and medication.

Average comparison in addiction relapse in two groups showed that the difference is significant and reducing rate is more in group therapy than Methadone treatment.

These finding are match with research results of Yazdanfar [10], Raadi [13], Koshki [14], Marlatt et al. [5], Carroll [3], Rezaei [8] and Molavvi et al. [9].

The result of the first minor hypothesis investigation: remedial methods have different effect on different age groups on reducing addiction relapse.

According to acquired results of this research, it can say that interaction of subject ages with type of remedy influence on reducing addiction relapse, but there is another result of Schaffe's test that addicted age is not determined factor for reducing addiction relapse lonely.

These findings are match with research results of the Ahari [15] showed that there is a relationship between age and quit addiction and stability in quitting and effect on reducing relapse. In addition, it had consistence by Yazdanfar [10] that has not find meaningful statistic idea that only the factor of age in controlling addiction of addicted and their relapse.

The results of second minor hypothesis investigation: research based on that onset of drug use with remedial methods effect reducing addiction relapse.

According to acquired results of this research, it was shown that the onset of drug use doesn't have an effect on reducing addiction relapse and this result doesn't match with former result by Abolghasemi [16] who believed the onset of drug use effects reducing addiction relapse. Of course, one result of these disputes can searched in type of remedy. Since Methadone treatment and CBGT had been taken as remedial method, in this research, while in Abolghasemi study, medication is only used. CBGT is a factor that causes increasing self-esteem and selfefficacy in addicted person as presented by Kiani [17] and Keshavarz [18]. According to Carroll et al. research [3], cognitive-behavioral therapy is a method that is used to teach problem - solving skills to an addicted person and self- confidence and ventured force feeling invigorate in a person. Consequently, the onset of drug use by attention to type of treatment method will not effect on reducing relapse.

The result of the third minor hypothesis investigation: research based on that age of remedial methods depends on marital status have different effect of reducing addiction relapse.

Results of this research show that marital status with treatment method doesn't have effect on reducing addiction relapse. These results match with findings of Yazdanfar [10], Heidari [11]. On the other hand, in a research done by showed that marriage can be a helpful factor in remedy of addiction alone. Of course, it is possible when there is no different between couples, because according to Behdush studies, family disputes and different between couples cause $71 \%$ of addiction relapse.

The results of fourth minor hypothesis investigation: research based on that age of job status of addicted with remedial methods effect reducing addiction relapse.

The result of this research showed that composed of job and remedial method does not affect reducing addiction relapse and it match by former finding of Asadi [12] and Yazdanfar [10] but doesn't match with Ahari [15] which said that there is significant relationship between job and treatment.

Naturally it is expected that the jobless are captured to relapse more than others during remedy but because of type of remedy used in this research and making motivation and self-efficacy in addicted, this different won't observed.

The results of fifth minor hypothesis investigation: research based on that age of remedial method by considering education rate have different effect on reducing addiction relapse.

The result of this analysis showed that reducing relapse in a compound group of "Diploma and higher level- group therapy" is the most rate ( $\mathrm{x}=3.71)$ and in "lower level of Diploma and Methadone therapy" group is lowest rate of reducing relapse $(\mathrm{x}=8.4)$.

Average comparison of four compound groups of education level and remedial methods showed that interaction of education level with remedial method have different effect on reducing addiction relapse, it means in comparison with average of groups "Diploma and uppergroup therapy" and "under Diploma and Methadone therapy" result showed that there is significant different between these two groups. But there is no significant difference among [(under Diploma-group therapy) and (under Diploma-Methadone therapy)], [(under Diplomagroup therapy) and (upper Diploma- group therapy)] and [(Diploma and upper-group therapy) and (Diploma and upper-Methadone therapy)]. These results are equal with Yazdanfar [10], Asadi [12], Ahari [15], Fazeli and Molavvi [19] who believed education level with remedy does not have significant effect on relapse rate.

In the future studies, this remedial method could be studied in more centers and in a longer period of time. It can be done on a special group or certain mob such as between urban bus drivers or government employees too and could be also separated using drugs from each other, could be investigated and remedied just a group of addicts who use same drug.

\section{References}

1. Velasquez MM, Maurer C, Crouch C, Diclemente C (2001) Group treatment for substance abuse: A stage of change therapy manual. Guilford Publications.

2. Teesson M, Hall W, Lynskey M, Degenhardt L (2000) Alchol and drug use disorders in Australia. Archives of General Psychiatry 49: 876-880.

3. Carroll K (1998) Therapy manuals for drug addiction, a cognitive behavioral approach treating cocaine addiction. National Institute on Drug Abuse.

4. Rogers R, McMillin C (1992) Freeing someone you love from alcohol and othe drugs: A step-by-step plan starting today. Body Press/Perigee Books, New York.

5. Alan Marlatt G, Donovan DDM (2005) Relapse prevention: Maintenance strategies in the treatment of addictive behaviors. Guilford Press, New York.

6. Coleman JC (1979) Abnormal psychology and modern life. Scott Foresman.

7. Schuckit MA (1999) New findings in the genetics of alcoholism. JAMA 281 1875-1876. 
Citation: Mesrahi T, Sedighi M, Shirali M (2016) The Effect of Cognitive-Behavioral Group Therapy on Decrease in Addiction Relapse in Randomly Assigned Addicts under Drug Therapy: A Statistical Analysis. Int J Neurorehabilitation 3: 214. doi:10.4172/2376-0281.1000214

8. Rezaei SI (2002) Effect on behavioral-cognitive remedy in reducing depression rate and relapse of abusing drug. Scientific-Research Journal of Medical and Hygienic University 8: 34-42.

9. Mehrabi, Molavvi, Neshatdost T (2005) The effect of structured group therapy and family psycho-education on the reduction of the frequency of relapse on out-patient addicts in isfahan addicts rehabilitation center. Journal of Social Sciences and Humanities of Shiraz University 45: 48-55.

10. Yazdanfar (2002) Investigation of effect of psychology service and counsel with medical services in reducing addiction relapse in detoxification addicted. M.A thesis Payam Noor University, Karaj.

11. Heidari S (2008) Causes of Addiction Relapse in N.A Group. M.A thesis Payam Noor University, Karaj.

12. Ali A (2001) Investigation of effect of attending in narcotics anonymous group (N.A) on relapse addiction rate. Isfahan social welfare quit addiction clinic. Thesis of M.A Islamic Azad University.

13. Raadi (2001) Investigate of effective factor of returning addicted to use drug in patients coming to Kordestan quit addition center. MA thesis of counseling, Isfahan psychology and training science university.
14. Koshki M (2003) Investigation of effect of structural group therapy \& training family in reducing relapse in drug depending patients. M.A thesis of Isfahan University.

15. Ahari S (2000) Effective factor of medication in addiction relapse in selfintroduced patients to society welfare addiction center. M.A thesis of Islamic Azad University.

16. Abolghasemi S (2006) The relation between behavior disorders and addiction M.A thesis of Islamic Azad University, Karaj.

17. Kiani J, Pakizeh A, Ostovar A, Namazi S (2010) Effectiveness of cognitive behavioral group therapy (C.B.G.T) in increasing the self-esteem and decreasing the hopelessness of ß-thalassemic adolescents. Iranian South Medical of Journal 13: 241-252.

18. Keshavarz A, Molavi H, Malekpourn M, Neshatdost HT, Paknahad Z (2012) The effect of cognitive- behavior therapy on weight self-efficacy, self-esteem and body mass index (BMI) in Iranian obese patients. Interdisciplinary Journal of Contemporary Research in Business 4: 267-272.

19. Fazeli, Molavvi (2002) Investigation of using drug among male addicted in Iran Journal of abusing drug 1: 67-88. 